\title{
THE BIOASSAY OF ADRENAL CORTICOIDS IN THE URINE OF PATIENTS WITH CONGESTIVE HEART FAILURE
}

\author{
By ALVIN E. PARRISH \\ (From the Department of Physiology, George Washington University School of Medicine, \\ Washington, $D . C$.)
}

(Received for publication June 14, 1948)

Futcher and Schroeder (1) and Warren and Stead (2) suggested that changes in endocrine activity might be present in congestive heart failure and might explain some of the symptoms such as edema and sodium retention. Merrill, Morrison, and Brannon (3) found an increased concentration of renin in the renal venous blood. No other reports of endocrine changes in congestive heart failure appear in the literature. Since sodium and water retention are known to occur following administration of adrenal cortical hormones, especially desoxycorticosterone, studies were undertaken to determine if the urine of patients in congestive heart failure contained increased amounts of corticoid substances.

\section{METHODS}

Ten male patients with congestive heart failure were selected at random from the Gallinger Municipal Hospital. These represented four cases of hypertensive heart disease, one of rheumatic heart disease, four of arteriosclerotic heart disease, and one of chronic cor pulmonale associated with asthma. Their ages ranged from 28 to 70 years, and all but two were negroes. The study was restricted to males to eliminate any possible interference due to changes in the menstrual cycle. Six medical students, none of whom had any evidence of heart disease, were used as control subjects. Twenty-four hour samples of urine were collected without preservatives. In the case of the heart failure patients these were collected as soon after admission as possible, usually within the first 48 hours. The first stage of extraction was carried through in all instances within 12 hours after the collection was made.

Urinary corticoids were extracted by the method of Venning, Kazmin, and Bell (4) ; and the extracted material was stored in the refrigerator until used. Before use this material was taken up in $6 \mathrm{cc}$. of 10 per cent ethanol so that each cubic centimeter of the resulting solution represented a four-hour excretion of corticoids.

This material was assayed on young male rats of the Sprague-Dawley strain, using the survival time of adrenalectomized rats as one method of assay $(5-7)$. The animals ranged in weight from 70 to $120 \mathrm{gm}$. Immediately after adrenalectomy these rats were placed on a diet of dog biscuit with 1 per cent sodium chloride and
5 per cent dextrose in their drinking water. After two to four days they were considered ready for use. At 9:00 a.m. of the initial day they were divided into cages of from five to ten rats and placed on a sodium-free diet (Table I) with distilled water for drinking. At 1:00 p.m. of this day they were given subcutaneously their first injection of $0.05 \mathrm{cc}$. of the alcoholic solution of corticoids. This was repeated at 12 -hour intervals as long as the animals survived. With each assay at least one cage was given extract of normal urine and one cage was given 10 per cent ethanol, using the same size dose. Each cage of animals was checked every eight hours for deaths and the survival time recorded in hours.

TABLE I

Sodium-free diet (29)

Casein (vitamin free)

Crisco

Starch

Dèxtrose

Salt mixture*

Distilled water

Thiamine hydrochloride

Riboflavine

Calcium pantothenate

Pyridoxine

Choline

Niacinamide

Vitamin Af

Vitamin $\mathbf{K}$

Vitamin Df

Alpha tocopherol\$

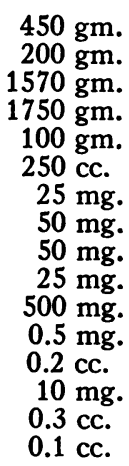

* Modified Hubbell salt mixture made without sodium salts $(30)$.

$\dagger 250,000$ units per cc.

$\$ 2 \mathrm{mg}$. per cc. of calciferol.

$50 \mathrm{mg}$. per cc.

Glycogenic activity was assayed by using male rats weighing 140 to $180 \mathrm{gm}$. (8). These were adrenalectcmized and placed on a diet of dog biscuíts and a solution of 1 per cent $\mathrm{NaCl}$. Three days following adrenalectomy these rats were taken off food for 24 hours. Starting at 6:00 a.m. on the day following this fast they were each given $0.20 \mathrm{cc}$. of the pooled urinary extracts (as described in the results) every hour for seven consecutive hours. One to two hours after the last injection they were given $0.2 \mathrm{gm}$. of sodium evipal intraperitoneally, and approximately $1 \mathrm{gm}$. of liver was removed and plunged into hot 30 per cent $\mathrm{KOH}$. Using the method of Good, Kramer, and Somogyi (9) the liver glycogen was isolated and hydrolyzed and the resulting glucose determined by the Shaffer-Somogyi method 


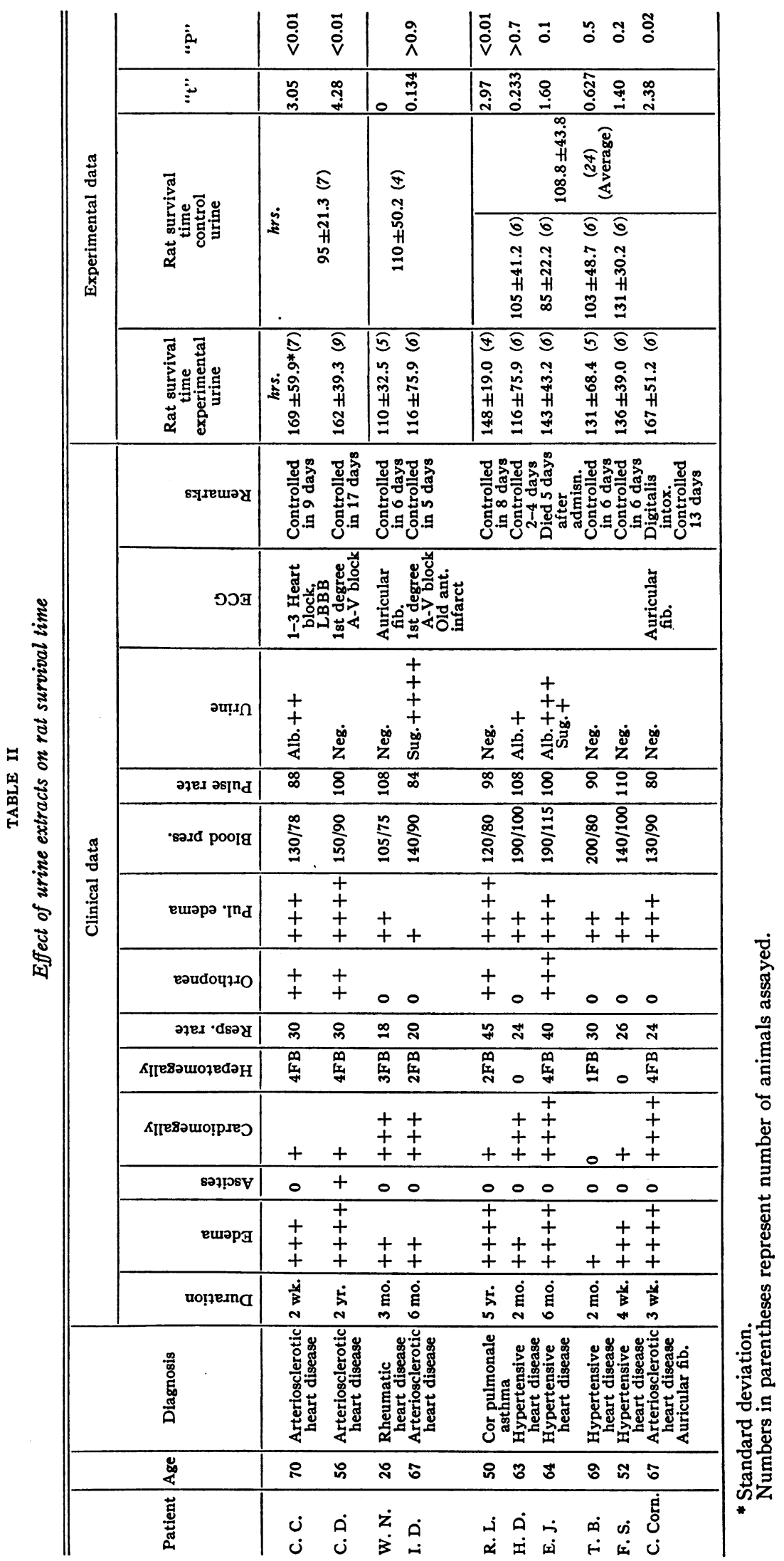


(10). The results were then expressed as mg. of glucose per $100 \mathrm{gm}$. of body weight.

The statistical significance of the data was determined by obtaining the value of " $P$ " corresponding to the calculated value of " $t$ " for the difference between the means of the results obtained in the experimental and the control animals (11).

\section{RESULTS}

The effect of urine extracts on the survival time of adrenalectomized rats on a sodium-free diet is summarized in Table II. Four urine extracts of patients with congestive heart failure produced a significant prolongation of the survival time of adrenalectomized rats over that of normal subjects when these were assayed simultaneously. The remaining six did not. Correlating this with the clinical findings, it can be seen that these former four patients were sicker than the remainder with one exception, E. J. Three of the four had orthopnea, all had three to four plus peripheral edema, and three to four plus pulmonary edema. Clinically, E. J. would also fall into this group; but his urine did not prolong the lives of the experimental animals significantly. Of the former group, three had arteriosclerotic heart disease and one had chronic cor pulmonale. In the latter group there were four cases of hypertensive heart disease, one of arteriosclerotic heart disease, and one of rheumatic heart disease.

In order to show that adrenalectomized animals would live under the conditions of the experiment if given one of the cortical hormones, 12 adrenalectomized rats were given subcutaneously $0.5 \mathrm{mg}$. of desoxycorticosterone acetate in propylene glycol twice daily. The procedures used were the same as those used in animals receiving injections of urine extracts. There were no deaths during the desoxycorticosterone injections which were continued for 216 hours. After these injections were stopped the animals lived an average of $194 \pm$ 109.1 hours. The long survival time of these rats subsequent to discontinuing the desoxycorticosterone was possibly due to the slow absorption of the hormone in some animals.

In order to show that the lives of adrenalectomized animals would not be prolonged by the solvent ( 10 per cent alcohol) alone, 25 animals were given 10 per cent alcohol using the same size dose and procedures as with those animals receiving urine extracts. These animals lived an aver- age of $108 \pm 38.0$ hours. This value is approximately the same as the average for the survival time of animals receiving normal urine extracts. (95.3 \pm 44.3 hours).

In practically all animals receiving the urinary extracts there were observed toxic reactions. Animals became sluggish within two to four days after beginning the injections. Rats weighing less than $70 \mathrm{gm}$. were not used since it was found that they died very early in a trial run ( 50.5 hours). Room temperature could not be controlled satisfactorily, and some animals died on cold nights. These factors are probably responsible for the large standard deviations in some instances.

Based on the clinical and experimental findings, the urine extracts were pooled into two groups. Group A consisted of those patients who were the sickest and whose extracts resulted in a significant

TABLE III

Comparison of glycogenic activity of urine extracts from normal subjects and from heart failure patients

\begin{tabular}{|c|c|c|}
\hline Extract & $\begin{array}{l}\text { Average liver glycogen } \\
(\mathrm{mg} . / 100 \mathrm{gm} \text {. of } \mathrm{rat})\end{array}$ & "P" \\
\hline $\begin{array}{l}\text { Control urine } \\
\text { Experimental urine: } \\
\text { Group A } \\
\text { Group B }\end{array}$ & $\begin{array}{l}0.985 \pm 1.56^{*}(8) \dagger \\
27.18 \pm 8.27^{*}(5) \\
24.13 \pm 9.04^{*}(5)\end{array}$ & $\begin{array}{l}<0.01 \\
<0.01\end{array}$ \\
\hline
\end{tabular}

* Standard deviation of the group.

$\dagger$ Numbers in parentheses represent number of animals assayed.

increase in survival time in adrenalectomized rats (urine extracts of patients C. C., C. D., R. L., and C. Corn.). E. J. was also placed in this group because clinically he belonged there and it was felt the survival time produced by his extracts was similar to that of this group although it was not statistically significant. Group B consisted of those patients who were not so sick and whose extracts resulted in no increase in survival time (urine extracts of patients W. N., I. D., H. D., T. B., and F. S.). These two pooled groups were used in the assay of the glycogenic activity of the urine extracts. The results are given in Table III. Both groups show a marked increase of glycogenic activity over that of control urine extract. The slight difference between the two experimental values was not evaluated because of the small number of animals used. 


\section{DISCUSSION}

The results of this study indicate that there is an increase in the urinary excretion of corticoids in patients with congestive heart failure. Of the ten patients studied, four who appeared clinically to be the sickest, excreted substances which prolonged the life of adrenalectomized rats while the remaining six did not. There was one patient who clinically belongs in this group whose urine extracts did not prolong the life of adrenalectomized rats. Both of these groups of patients, however, excreted an increased quantity of glycogenic corticoids. An increase of corticoid substances in the urine has been considered as an indication of increased adrenal cortical activity (47). There is, however, in these patients another factor which must be considered. All but two of the patients had liver enlargement; and since the liver plays an important role in the inactivation of steroid hormones (12), the question arises that in these cases there might have been enough liver damage to cause only an apparent increase in corticoid secretion rather than a true increase in corticoid production. Some authors (13) report liver dysfunction in a large percentage of patients with heart failure, but this cannot be correlated with the degree of failure (14).

Increased adrenal cortical activity in other instances is believed to be the result of a reaction to various "non-specific stimuli" (15). Of these anoxia has been shown to produce increased adrenal cortical activity (15-18) and Langley and Clarke (16) believe that disturbances in acid-base balance resulting from hyperventilation can stimulate the adrenal cortex. Both anoxia and hyperventilation are present in patients with heart failure and the increase in corticoids found in this study possibly represents adaptation to these nonspecific stimuli.

With an increase in adrenal cortical activity sodium retention would be expected, since some of the cortical hormones, especially desoxycorticosterone, act on the renal tubules to promote the reabsorption of sodium from the glomerular filtrate $(19,20)$.

Other investigations (21-23) indicate that the primary cause of sodium retention in heart failure is a decrease in renal blood flow and glomerular filtration which results from a shunting of blood away from the glomeruli secondary to renal vascular changes. Merrill (21) and Mokotoff, Ross, and Leiter (22) have concluded that there is no increase in the reabsorption of sodium in heart failure but that its reabsorption is proportional to the glomerular filtration rate. This suggests either that the adrenal corticoid production is not increased sufficiently to affect sodium reabsorption in heart failure or that the adrenal corticoids act on the renal vascular system. Experimental evidence to support the latter is inconclusive. Talbott, Pecora, Melville, and Consolazio (24) studied renal function in patients with Addison's disease and believe that the decreased renal function observed was due to a decreased tone of the efferent arterioles of the kidney and that this was corrected following the administration of desoxycorticosterone. No changes in renal function were observed in normal individuals following the administration of desoxycorticosterone acetate. Waterhouse and Keutmann (25) believe that in Addison's disease desoxycorticosterone produces a vasoconstrictor effect on the vascular system of the kidney. Other investigators have produced changes in the kidney with desoxycorticosterone $(15,20,26,27)$. Swingle (28) believes that desoxycorticosterone may affect the tone of arterioles. At the present time it seems more likely that the increase in corticoid excretion represents a result rather than a cause of the symptoms seen in heart failure. However, because of the close relation between clinical symptoms and the increase in corticoid excretion, further investigation is to be undertaken.

\section{SUMMARY}

1. The urine of ten patients in congestive heart failure was studied for the presence of adrenal corticoids and compared with normal control urine.

2. Of these ten patients, four showed an increase of corticoids over that found in normal urine which prolonged the life of adrenalectomized rats.

3. An increase in corticoids with glycogenic activity was observed in urine obtained from heart failure patients over that of urine obtained from normal control subjects.

4. The possible place of increased adrenal cortical activity in heart failure is discussed. 


\section{ACKNOWLEDGMENT}

The author wishes to express his appreciation to Dr. Errett C. Albritton, Dr. Abraham Dury, and Dr. Chester E. Leese of the Department of Physiology, George Washington University, for their encouragement and criticism of this work.

\section{BIBLIOGRAPHY}

1. Futcher, P. H., and Schroeder, H. A., Studies in congestive heart failure; II. Impaired renal excretion of sodium chloride. Am. J. M. Sc., 1942, 204, 52.

2. Warren, J. V., and Stead, E. A., Jr., Fluid dynamics in chronic congestive heart failure; an interpretation of mechanisms producing edema, increased plasma volume and elevated venous pressure in certain patients with prolonged congestive failure. Arch. Int. Med., 1944, 73, 138.

3. Merrill, A. J., Morrison, J. L., and Brannon, E. S., Concentration of renin in renal venous blood in patients with chronic heart failure. Am. J. Med., 1946, 1, 468.

4. Venning, E. H., Kazmin, V. E., and Bell, J. C., Biological assay of adrenal corticoids. Endocrinology, 1946, 38, 79.

5. Venning, E. H., Hoffman, M. M., and Browne, J. S. L., The extraction of cortin-like substances from human post-operative urine. Endocrinology, 1944, 35, 49.

6. Grollman, A., and Firor, W. M., Studies on the adrenal; II. Extraction of cortical hormone from urine. Proc. Soc. Exper. Biol. \& Med., 1932, 30, 669.

7. Dorfman, R. I., Horwitt, B. N., and Fish, W. R., The presence of a cortin-like substance (cold protecting material) in the urine of normal men. Science, 1942, 96, 496.

8. Reinecke, R. M., and Kendall, E. C., Method for bioassay of hormones of the adrenal cortex which influence deposition of glycogen in the liver. Endocrinology, 1942, 31, 573.

9. Good, C. A., Kramer, H., and Somogyi, M., The determination of glycogen. J. Biol. Chem., 1933, $100,485$.

10. Shaffer, P. A., and Somogyi, M., Copper-iodometric reagents for sugar determination. J. Biol. Chem., 1933, 100, 695.

11. Croxton, F. E., and Cowden, D. J., Applied General Statistics. Prentice-Hall, Inc., New York, 1940, 305-331.

12. Selye, H., Textbook of Endocrinology. Université de Montréal, Montréal, Canada, 1947, p. 79.

13. Cantarow, A., Studies of hepatic function. II. In portal cirrhosis and congestive heart failure. Arch. Int. Med., 1935, 56, 521.

14. Lichtman, S. S., Diseases of the Liver, Gallbladder, and Bile Ducts. Lea and Febiger, Philadelphia, 1942, 670-676.

15. Selye, $H$., The general adaptation syndrome and diseases of adaptation. J. Clin. End., 1946, 6, 117.

16. Langley, L. L., and Clarke, R. W., The reaction of the adrenal cortex to low atmospheric pressure. Yale J. Biol. \& Med., 1942, 14, 529.

17. Dohan, F. C., Effect of low atmospheric pressure on adrenals, thymus and testes of rats. Proc. Soc. Exper. Biol. \& Med., 1942, 49, 404.

18. Lewis, R. A., Thorn, G. W., Koepf, G. F., and Dorrance, S. S., Role of adrenal cortex in acute anoxia. J. Clin. Invest., 1942, 21, 33.

19. Harrison, H. E., and Darrow, D. C., Renal function in experimental adrenal insufficiency. Am. J. Physiol., 1939, 125, 631.

20. Swingle, W. W., and Remington, J. W., Role of adrenal cortex in physiological processes. Physiol. Rev., 1944, 24, 89.

21. Merrill, A. J., Edema and decreased renal blood flow in patients with chronic congestive heart failure: evidence of "forward failure" as primary cause of edema. J. Clin. Invest., 1946, 25, 389.

22. Mokotoff, R., Ross, G., and Leiter, L., Renal plasma flow and sodium reabsorption and excretion in congestive heart failure. J. Clin. Invest., 1948, $27,1$.

23. Seymour, W. B., Pritchard, W. H., Longley, L. P., and Hayman, J. M., Jr., Cardiac output, blood and interstitial fluid volumes, total circulating serum protein, and kidney function during cardiac failure and after improvement. J. Clin. Invest., 1942, 21, 229.

24. Talbott, J. H., Pecora, L. J., Melville, R. S., and Consolazio, W. V., Renal function in patients with Addison's disease and in patients with adrenal insufficiency secondary to pituitary pan-hypofunction. J. Clin. Invest., 1942, 21, 107.

25. Waterhouse, C., and Keutmann, E. H., Kidney function in adrenal insufficiency. J. Clin. Invest., 1948, 27, 372.

26. Grollman, A., Harrison, T. R., and Williams, J. R., Jr., The effect of various sterol derivatives on the blood pressure of the rat. J. of Pharm. \& Exper. Therap., 1940, 69, 149.

27. Knowlton, A. I., Stoerk, H. C., Seegal, B. C., and Loeb, E. N., Influence of adrenal cortical steroids upon blood pressure and rate of progression of experimental nephritis in rats. Endocrinology, 1946, 38, 315.

28. Swingle, W. W., Parkins, W. M., and Remington, J. W., The effect of desoxycorticosterone acetate and of blood serum transfusions upon the circulation of the adrenalectomized dog. Am. J. Physiol., 1941, 134, 503.

29. Albritton, E. C., Unpublished data.

30. Hubbell, R. B., Mendel, L. B., and Wakeman, A. J., A new salt mixture for use in experimental diets. J. Nutrition, 1937, 14, 273. 